\title{
$\mathrm{BIM}$ 속성분류체계 구축을 위한 속성입력 자동화 프로그램 구현
}

\author{
남 정 용 $^{1 \dagger} \cdot$ 주 재 하 $^{2}$.김 태 형 ${ }^{3}$
}

${ }^{1}$ (주)고려소프트웨어 건설정보사업부 대표이사, ${ }^{2}$ (주)고려소프트웨어 건설정보사업부 팀장, ${ }^{3}$ (주고려소프트웨어 건설정보사업부 과장

\section{Implementation of Property Input Automation Program for Building Information Modeling (BIM) Property Set}

\author{
Jeong-Yong $\mathrm{Nam}^{1 \dagger}$, Jae-Ha Joo ${ }^{2}$ and Tae-Hyung $\mathrm{Kim}^{3}$ \\ ${ }^{1}$ CEO, Smart Construction Business, Koryosoftware Inc., Seoul, 06650, Korea \\ ${ }^{2}$ Team Manager, Smart Construction Business, Koryosoftware Inc., Seoul, 06650, Korea \\ ${ }^{3}$ Manager, Smart Construction Business, Koryosoftware Inc., Seoul, 06650, Korea
}

\begin{abstract}
Building Information Modeling (BIM) tools have not only increased the use of technology in the design process, but also increased the need for more information standard systems. The object classification system consists of 327 types of construction results obtained from 25 kinds of facilities, 174 types of parts, and 207 types of construction parts. In the previous study, the property classification system was developed into 4 major classifications, 13 middle classifications, 58 small classifications (category), and 333 attribution information of roads and rivers. It is extremely difficult to input the property information according to such extensive object classification. In addition, the development of external applications such as Revit plug-ins has created a need to automate specific and repetitive tasks. Therefore, following the BIM property classification system, an attribute input program was implemented for the system to enhance the productivity and convenience of the BIM users.
\end{abstract}

Keywords : BIMclassification, propertyset, Pest input program, information technology

\section{1. 서 론}

\section{1 연구의 배경 및 목적}

BIM(Building Information Modeling)은 AEC(Architecture, Engineering, and Construction) 분야에서 생산성 향상을 위한 전 세계적으로 공인된 방법론이며, 다양한 솔루션이 지속해서 개발되고 있다. 또한, 국토교통부에서는 다양한 정책과 과제 를 통해서 4차 산업혁명과 연계할 수 있는 BIM 정보기술의 추 진을 내세우고 있다. 그런데도 공공기관들은 각각 독자적으로 $\mathrm{BIM}$ 개발을 추진하고 있으나 정보표준체계 개발과 상호연계 노력은 아직도 부족한 실정이다.

최근 건설기술연구개발 사업에서는 2017 년도에 객체분류 체계(안)를 개발하였으나, 객체는 정보 속성체계와 연계, 통

\footnotetext{
${ }^{\dagger}$ Corresponding author:

Tel: +82-2-563-2707; E-mail: krsoft1004@gmail.com Received October 15 2019; Revised November 13 2019; Accepted November 262019

C) 2020 by Computational Structural Engineering Institute of Korea
}

합 구현되어야 정보모델로서의 궁극적인 지능형 정보화의 목적을 달성할 수 있게 됨에 따라 속성정보체계의 개발이 시 급히 진행되었으며, 그에 따라 BIM 표준분류체계가 개발되 었다.

따라서, 본 연구에서는 2020년 BIM의 실무도입에 앞서 $\mathrm{AEC}$ 분야의 세부분야별 $\mathrm{BIM}$ 속성분류체계를 따르면서 속성 을 입력할 수 있는 프로그램을 개발하고자 한다.

\section{$1.2 \mathrm{BIM}$ 정보분류체계 모델링 장점}

정보분류체계가 제대로 구현될 때 수많은 이점을 제공할 수 있으며 건설 프로젝트의 모든 단계에서 적용될 수 있다. 프로 젝트 중에 다양하고 효율적인 방법을 제공하여 의사결정을 효 과적으로 도와주며 장점을 나열하면 다음과 같다.

This is an Open-Access article distributed under the terms of the Creative Commons Attribution Non-Commercial License(http://creativecommons. org/licenses/by-nc/3.0) which permits unrestricted non-commercial use, distribution, and reproduction in any medium, provided the original work is properly cited. 
- 통합 데이터베이스 기반의 표준분류체계를 갖춘 체계적 인 관리방안 마련

- 계획된 시공일정의 정보개선으로 인한 현장 효율성 증대

- BIM 정보의 품질의 일관성 유지

- 효과 검색 제공으로 $\mathrm{BIM}$ 설계 시 생산성 증대

- 라이브러리 DB화

- 지속적인 자료축적

- 의사결정을 위한 기초자료

- 오류 및 누락 감소

- 운영 및 유지보수 개선

\section{3 연구의 범위 및 방법}

본 연구는 객체분류체계와 속성분류체계로 구분된 BIM 표 준분류체계를 기반으로 하여 속성입력 프로그램을 개발하고 자 하였다.

$\mathrm{AEC}$ 분야에서도 기초이기 때문에 가장 시급하다고 할 수 있는 SOC(Social Overhead Capital) 분야는 도로, 하천, 철도, 항만, 수자원 및 택지개발 등 대상 시설물이 광범위하고 종류 도 매우 다양하다. 본 연구에서는 도로 및 하천을 주된 연구범 위로 하고, 향후 확장성을 고려하여 SOC 분야의 다양한 시설 물을 대상으로 가능한 방안을 마련하여 제시하였다.

\section{4 선행연구 및 이론적 고찰}

\subsection{1 속성분류체계 관련 연구 동향}

$\mathrm{BIM}$ 정보분류체계에 관한 연구가 다양하게 이루어져 왔으 나, 주로 건축 분야로 한정되어 있었다. 또 철도 교량의 BIM 구 축을 위한 3 차원 모델자동화생성 시스템 개발(Lee et al., 2018) 에서는 속성정보입력 자동화보다는 형상에 생성에 치우친 상 태이다. BIM 도입을 위한 정보체계에 관해서는 연구가 많이 부족한 상황이다. 속성분류체계와 관련된 선행 연구는 Table 1 과 같다.

최근에는 모델의 계층구조에 따라 필요한 속성정보를 채택 하여 구성하고 설정할 수 있도록 속성분류체계가 개발되었다. 속성정보는 사업정보, 시설정보, 구조물정보, 부위공법정보, 객체(BIM Library)정보를 모델 수준에 따라 채택 구성하는 방 법을 제시하는 연구가 수행되었다.

\subsection{2 인프라 BIM 속성분류체계}

국토교통부는 2017년도에 이미 'BIM 기반 도로·하천 시설 물의 건설사업정보 통합관리기술 개발’ 사업을 통해 도로 및 하천 분야 객체분류체계(안)를 개발한 바 있다.
Table 1 Previous study of related BIM attribute classification establishments

\begin{tabular}{|c|c|c|}
\hline Author & Study Name & Contents \\
\hline $\begin{array}{l}\text { Nam, J,Y., } \\
\text { Kim M.J. }\end{array}$ & $\begin{array}{c}\text { A Study on the Development of } \\
\text { BIM Property Classification } \\
\text { System in Road and River Field } \\
\text { (Nam and Kim, 2019) }\end{array}$ & $\begin{array}{c}\text { To suggest the } \\
\text { classification for BIM } \\
\text { properties in BIM library }\end{array}$ \\
\hline $\begin{array}{l}\text { Shin, J.H., } \\
\text { Choi, J.S., } \\
\text { Kim, I.H., } \\
\text { Yoon, D.Y. }\end{array}$ & $\begin{array}{l}\text { A study on Development of } \\
\text { Integrated Management } \\
\text { System for BIM Property } \\
\text { Information } \\
\text { (Shin et al., 2016) }\end{array}$ & $\begin{array}{c}\text { To suggest the integrated } \\
\text { management system for } \\
\text { property information of } \\
\text { BIM library }\end{array}$ \\
\hline $\begin{array}{l}\text { Lee, S.I., } \\
\text { Han, J,S., } \\
\text { Jo, C.W. }\end{array}$ & \begin{tabular}{|c|} 
A Basic Study on Property \\
Structure Standardization based \\
on BIM Information \\
Framework \\
(Lee et al., 2015)
\end{tabular} & $\begin{array}{c}\text { To suggest standardized } \\
\text { BIM library property } \\
\text { system based on BIM } \\
\text { information framework }\end{array}$ \\
\hline $\begin{array}{l}\text { Lee, E.B., } \\
\text { Kim, D.H. }\end{array}$ & $\begin{array}{c}\text { A Study on the Implementation } \\
\text { Method of the Object } \\
\text { Classification System and } \\
\text { Property Information for } \\
\text { Vitalizing Standardized BIM } \\
\text { Library } \\
\text { (Lee and Kim, 2015) }\end{array}$ & $\begin{array}{l}\text { To define BIM Library } \\
\text { classification system } \\
\text {-To suggest property } \\
\text { information and standard } \\
\text { of BIM library }\end{array}$ \\
\hline $\begin{array}{l}\text { Yu, J.H., } \\
\text { Chin, D.B., } \\
\text { Kang, B.C. }\end{array}$ & $\begin{array}{c}\text { Proposal for Standard } \\
\text { Parameter System of } \\
\text { Architecture Object on Revit } \\
\text { (Yu et al., 2011) }\end{array}$ & $\begin{array}{l}\text { To define BIM structure } \\
\text { of properties and propose } \\
\text { standard property system }\end{array}$ \\
\hline $\begin{array}{l}\text { Lee, J.M., } \\
\text { Kim, H.S., } \\
\text { Lee, I.S. }\end{array}$ & $\begin{array}{c}\text { Development of Automated 3D } \\
\text { Modeling System to Construct } \\
\text { BIM for Railway Bridge } \\
\text { (Lee et al., 2018) }\end{array}$ & $\begin{array}{c}\text { Development of } \\
\text { Automated 3D Modeling } \\
\text { System }\end{array}$ \\
\hline
\end{tabular}

이 객체분류체계(안)는 정보표준 측면을 고려하여 ISO 12006-2 기반의 건설정보분류체계의 피셋 개념을 일부 도입 하여 시설물을 계층적으로 분류하고, ISO 12006-3 기반의 객 체체계를 도입하여 BIM 정보체계 추이를 반영하였으며, BIM 공통포맷인 InfraBIM IFC-Road 정보구조를 반영하여 객체분 류체계를 개발하였다(Nam and Kim, 2018).

인프라 BIM의 속성분류체계는 객체분류와 연계하여 정보 모델을 구축하면서 필요정보의 요건을 정의한 것이다.

\section{$1.5 \mathrm{BIM}$ 정보입력방법}

$\mathrm{BIM}$ 객체에 대한 속성에 대한 자동생성 및 입력 등의 제어 관리를 수행할 수 있는 기능 모듈(Module)을 개발 구현하는 것 으로 (주)오토데스크 제품인 Revit 2018을 대상으로 패밀리 유 형(Element Type), 패밀리 유형 인스턴스(Element)에 대한 속 성 필드(Field)를 자동으로 생성하고 생성된 속성 필드(Filed) 에 속성 값(Value)을 자동으로 입력 제어할 수 있도록 개발 구 현하였다. 속성분류체계를 연계하여 WBS(Work Breakdown 
System), OBS(Object Breakdown System), CBS(Cost Breakdown System) 트리(Tree) 정보들을 활용할 수 있도록 하였다.

\section{2. 본 론}

\section{1 프로그램 구현 환경}

$\mathrm{BIM}$ 속성분류체계 속성입력에 필요한 모든 정보가 포함된 파일을 자동으로 생성하는 방법을 소개한다. Autodesk Revit 은 $\mathrm{BIM}$ 을 지원하고 건물 구조에 대한 정보를 생성 및 저장하 는 소프트웨어이다.

Revit에는 Microsoft Visual Studio에서 C \# 언어로 플러그인 을 개발하기 위한 API의 내장 기능이 있다. Add-in 프로그램으 로서 기존의 Revit 프로그램에 DLL 형태로 연동되며 개발된 모듈을 Revit 인터페이스에서 호출하는 형식으로 운영된다.

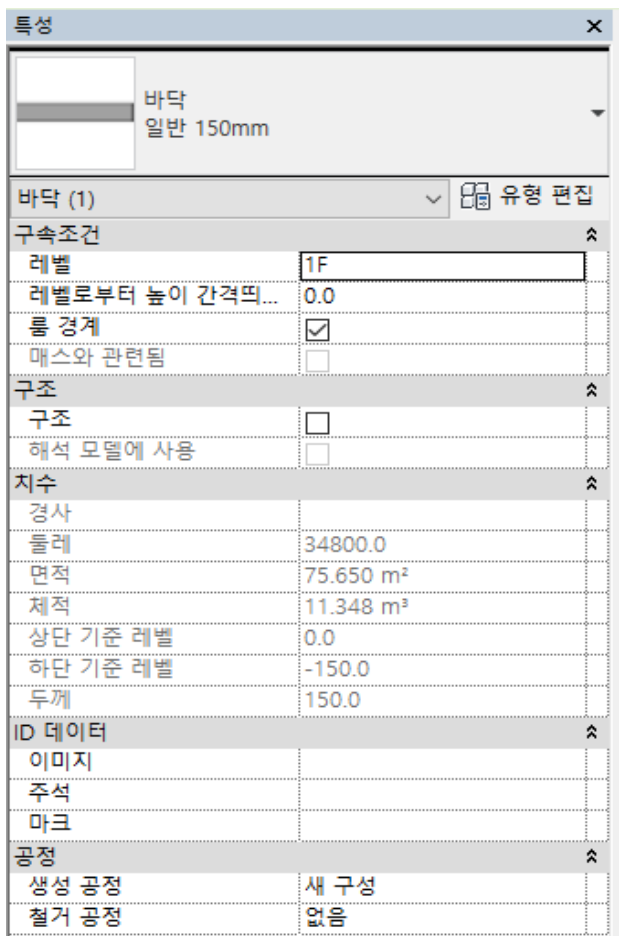

Fig. 1 Revit object general properties

Excel 파일에서 속성항목 데이터를 Revit 프로그램으로 불 러올 수 있다. 응용 프로그램(작성자가 개발 한)과 Autodesk Revit의 활용방식은 다음과 같다.

$\mathrm{BIM}$ 속성분류체계에서 제안된 방식으로 작성된 Excel 시 트에서 Revit으로 속성을 불러와 객체(패밀리)에 Mapping 하 여 프로그래밍한다.

Fig. 1 에서 보이는 바와 같이 일반 시스템 또는 사용자 작성
객체(패밀리)에는 속성분류체계가 없으므로 매개변수를 설정 하고 하나하나씩 속성을 입력하기에는 많은 시간과 오류가 발 생할 여지가 있다. 하지만 본 연구에서 개발된 프로그램을 사 용하여 작성하면 사용자에게 친숙한 Excel로 작성하기 때문에 데이터를 수정하기 쉽게 도와준다.

\section{2 제안 프로그램 순서도 및 구현}

상용컴포넌트에서 제공하는 Spreadsheet Control API를 통 하여 Excel 안에 있는 sheet의 Cell 정보를 가져올 수 있다. 또 한, Excel이 설치되어있지 않아도 Excel sheet 안의 정보를 가 져올 수 있다.

Revit SDK에서 제공하는 Revit API를 통하여 객체(패밀리) 의 속성을 추가하는 함수는 FamilyParameter AddParameter() 이다.

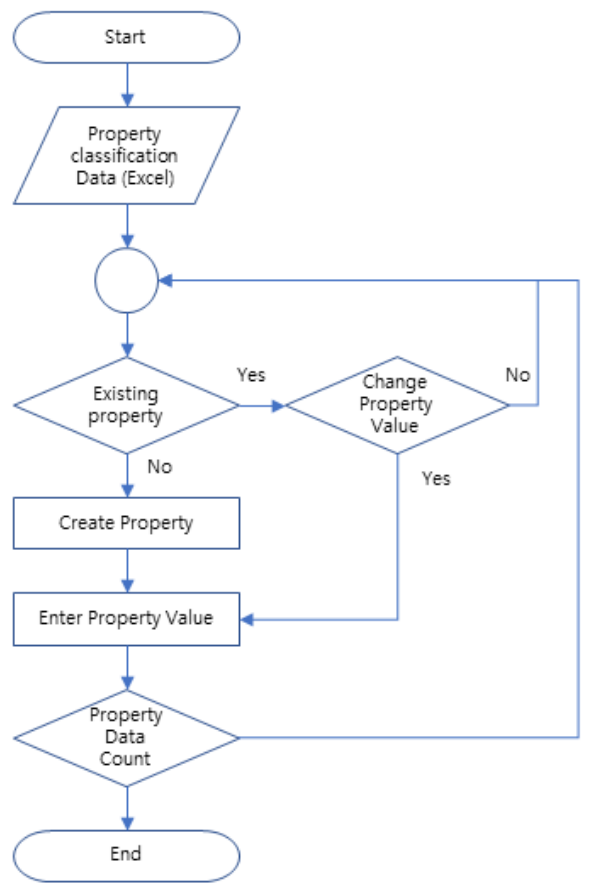

Fig. 2 BIM attribute classification system attribute information input flowchart

여러 가지 BIM 속성분류체계 정보들을 Fig. 2의 순서도처 럼 루프문을 통하여 한 번에 Revit 라이브러리에 입력할 수 있 도록 구현하였다.

Fig. 3은 프로그램의 핵심 코드 내용을 보여 준다. Excel에서 가져온 속성정보를 객체(패밀리)에 넣는 부분을 보여 주고 있 다. BIM 속성분류체계의 많은 속성정보를 분석하여 추가하는 과정이다. 


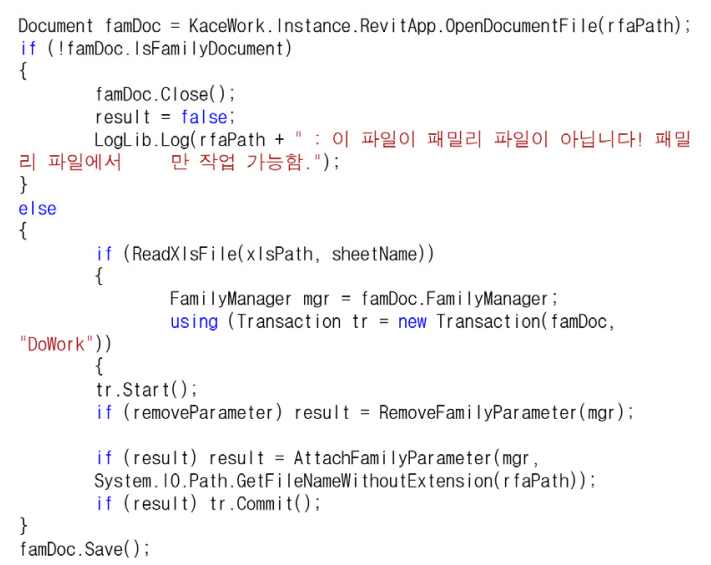

Fig. 3 Code to add excel property information to object(family)

\section{3 개발 프로그램의 동작 시현 및 출력 검증}

\subsection{1 프로그램 구현 동작}

Installer를 실행하면 Fig. 4와 같이 기본 폴더는 C:IProgram Data\Autodesk $\backslash$ ApplicationPlugins $\backslash$ 아래에 설치된다. 하위 Contents $2018 \backslash \mathrm{OBS}$ Library에는 Fig. 5와 같이 "도로 및 하천 분야 BIM 속성분류체계 개발방안 연구”의 분류체계에 따라 OBS 분류 폴더가 자동으로 생성된다. 해당 폴더에 맞게 BIM 속성분류체계 Excel 파일을 생성하여 넣어주면 프로그램의 실 행준비가 완료된다.

이후 Revit을 실행하면 Fig. 5 와 같이 보안경고 창이 나타나 고 항상 로드, 한 번 로드 버튼을 누르게 되면 Fig. 6과 같이 상 단메뉴에 Kace Pset Manager가 활성화되고 표준분류체계 작 성 활용 소프트웨어 그룹과 실행 아이콘들이 생성되어 있는 것 을 확인할 수 있다.

기본적으로 Revit은 Plug-in 시스템을 허용하는 데 Revit을 이용하는 것에 있어서 좀 더 편리하게 이용할 수 있도록 사용 자들이 3rd Party 형식으로 직접 프로그램을 설계하고 Revit 프 로그램 내에 프로그램을 확장할 수 있는 구조를 지원하고 있다.

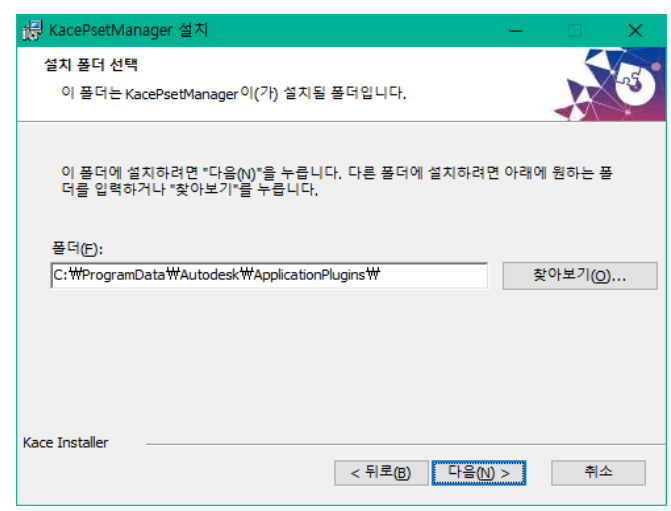

Fig. 4 Install screen

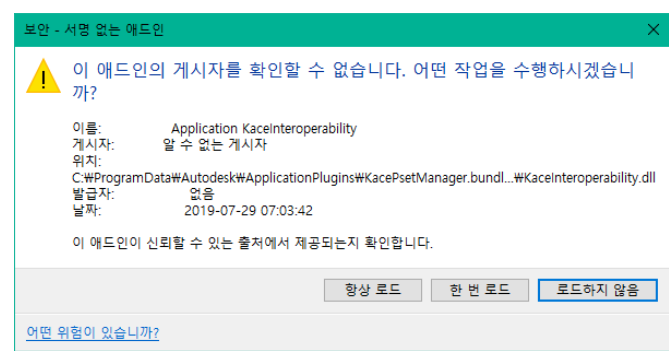

Fig. 5 Security warning window

프로그램의 핵심기능이 Revit 도면 파일을 읽어와야 하므로 독립적인 응용 프로그램보다Plug-In 식 프로그램 형태를 취하 였다. 모듈별 사용방법은 본 논문에서는 생략한다.

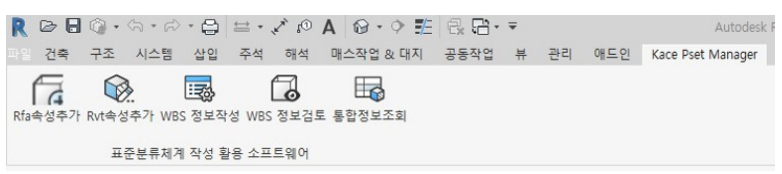

Fig. 6 Add-in custom kace pset manager tools

Fig. 6에서 보는 것과 같이 표준분류체계 작성 활용 소프트 웨어 중에 RFA 속성추가를 누르게 되면 Fig. 7(a)의 창이 나타 난다. 객체(패밀리)에 객체(패밀리)의 속성정보를 추가하는 모듈이다. 구성된 다른 OBS 폴더를 선택하거나 변경할 수 있 으며, $\mathrm{Rfa}$ (패밀리 파일)이 있는 폴더를 보고, Rfa에 속성을 추 가할 수 있다.

표준분류체계 작성 활용 소프트웨어 중에 Rvt속성추가를 누르게 되면 Fig. 7(b)의 창이 나타난다.

선택된 객체에 불러온 Excel 속성정보를 추가하는 모듈이 다. 선택된 속성 파일을 불러오거나 Fig. 8과 같이 Excel의 속 성정보를 볼 수 있다.

표준분류체계 작성 활용 소프트웨어 중에 WBS 정보작성을 누르게 되면 Fig. 7(c)의 창이 나타난다. 선택한 객체에 WBS 정보를 추가하거나 공간에 대한 위치 정보를 수정하는 모듈이 다. 도로와 하천에 대한 작업분류체계를 선택하여 일괄적으로 WBS 코드를 작성할 수 있으며, 선택된 WBS 분류 별로 수정할 수도 있다.

표준분류체계 작성 활용 소프트웨어 중에 WBS 정보검토를 누르게 되면 Fig. 7(d)의 창이 나타난다. Revit 파일 내 객체(패 밀리) WBS 속성정보가 오류 없이 작성되었는지 확인하고 수 정할 수 있는 모듈이다.

마지막으로 표준분류체계 작성 활용 소프트웨어 중에 통합 정보조회를 누르게 되면 Fig. 7(e)의 창이 나타난다. 표준속성 정보, $\mathrm{OBS}, \mathrm{WBS}, \mathrm{CBS}$ 의 모든 정보를 통합적으로 확인하는 모듈이다. 


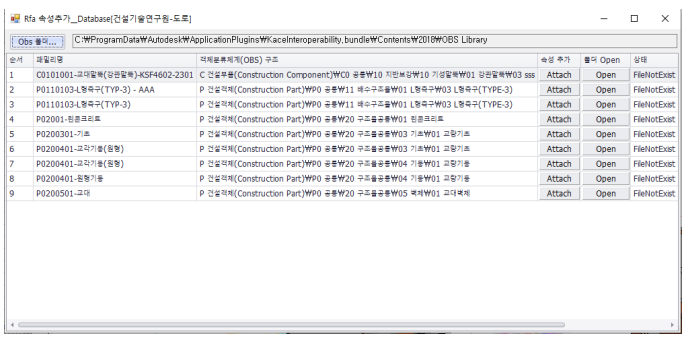

(a)

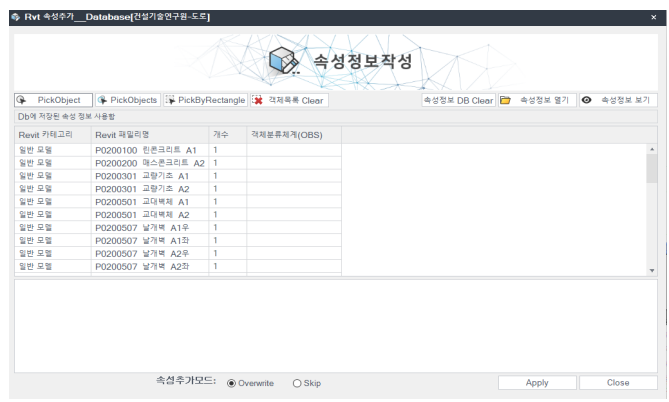

(b)

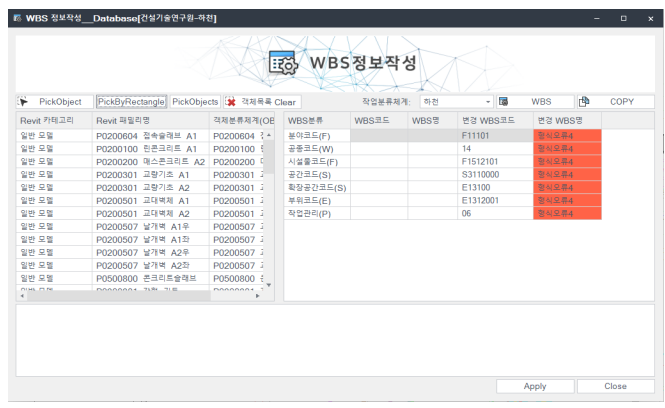

(c)

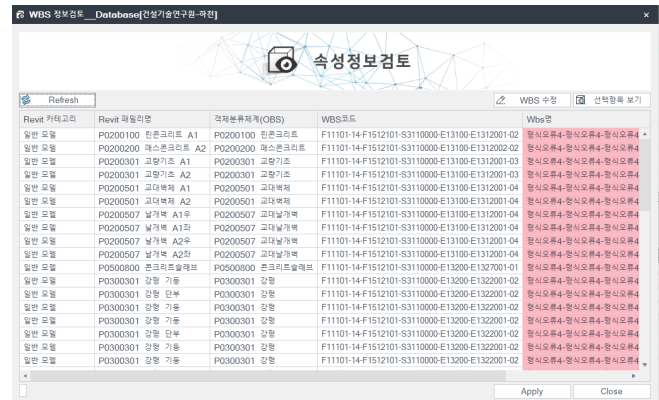

(d)

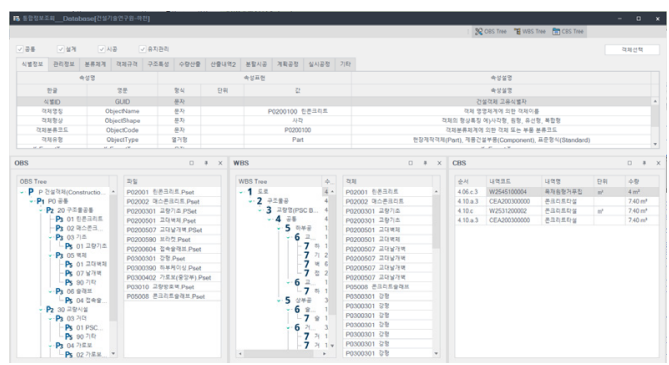

(e)

Fig. 7 Kace pset manager interface

(a) Rfa attribute added (b) Rvt attribute added (c) WBS information writing (d) WBS information review (e) Integrated information check

\subsection{2 프로그램 검증}

프로그램의 검증 방법은 Fig. 8 의 Excel 속성정보와 Revit 상 에서 볼 수 있는 객체(패밀리)의 정보를 대조하여 검증하는 방 법을 채택하였다.

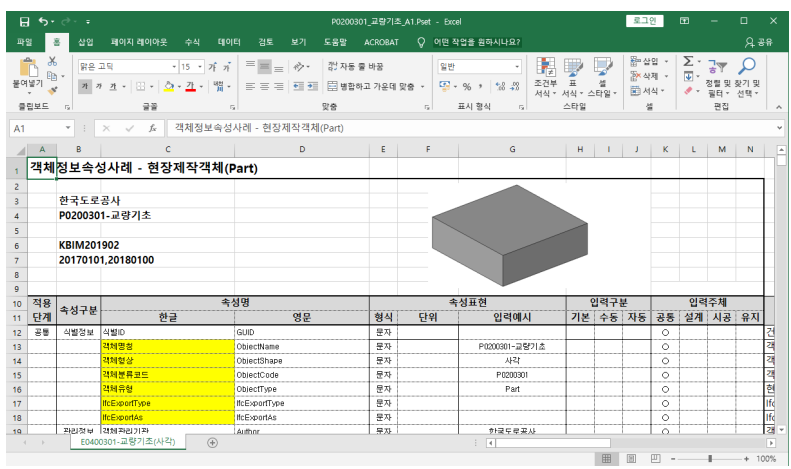

Fig. 8 View property information

Fig. 9에서 볼 수 있듯이 Excel 속성정보와 객체(패밀리)의 정보들을 대조해 보면 서로 상호 일치하는 것을 볼 수 있다.

상호 일치한다는 내용은 Excel 속성정보를 Revit에 추가하 였을 때에 모든 정보를 Revit에 Import 시킬 수 있는 것을 의미 하기 때문에 도면의 속성정보 수정이나 속성정보를 한눈에 보 기 위한 자료로써 오류 없이 사용자가 데이터를 직관적으로 불 수 있는 것을 의미한다.

또한, $\mathrm{BIM}$ 정보분류체계 모델링을 속성이 부여된 교량 정 보모델을 IFC $2 \times 3$ 포맷으로 변환하고 (주)고려소프트웨어에서 개발한 BIM 뷰어 KaceBIM을 통해 검토하였다. Fig. 10 의 좌 측은 KaceBIM의 WBS 정보구조, 우측은 속성분류체계가 반 영된 속성정보를 나타낸다.

\subsection{3 프로그램의 우수성}

1) ( $2 \mathrm{D}$ 속성정보 $\rightarrow 3 \mathrm{D}$ 속성정보) 기존 $2 \mathrm{D}$ 도면의 평면적 속 성정보방식에서 $3 \mathrm{D}$ 모델에 구성된 패밀리에 의한 입체 적인 3 차원 속정정보방식과 $3 \mathrm{D}$ 설계 방식 전환 대응 가능

2) (수동입력 $\rightarrow$ 자동입력) 기존 설계자가 직접 속성체계를 입력을 통해 생성하는 방식에서 도로 및 하천분야 속성 분류정보의 분석을 통한 자동분류 및 입력방식으로 개선

3) (입력누락 $\rightarrow$ 입력검토) 속성분류체계 입력시 Human Error에 의한 입력누락이 정보검토항목에 의한 검토방 식으로 정확하고 누락없는 속성분류체계 입력가능

4) (시간소요 $\rightarrow$ 시간절감) 수작업에 의한 속성입력 방식에 서 Excel Import에 의한 매핑방식을 활용하므로 설계데 이터의 수량산출 프로세스의 시간 절감 


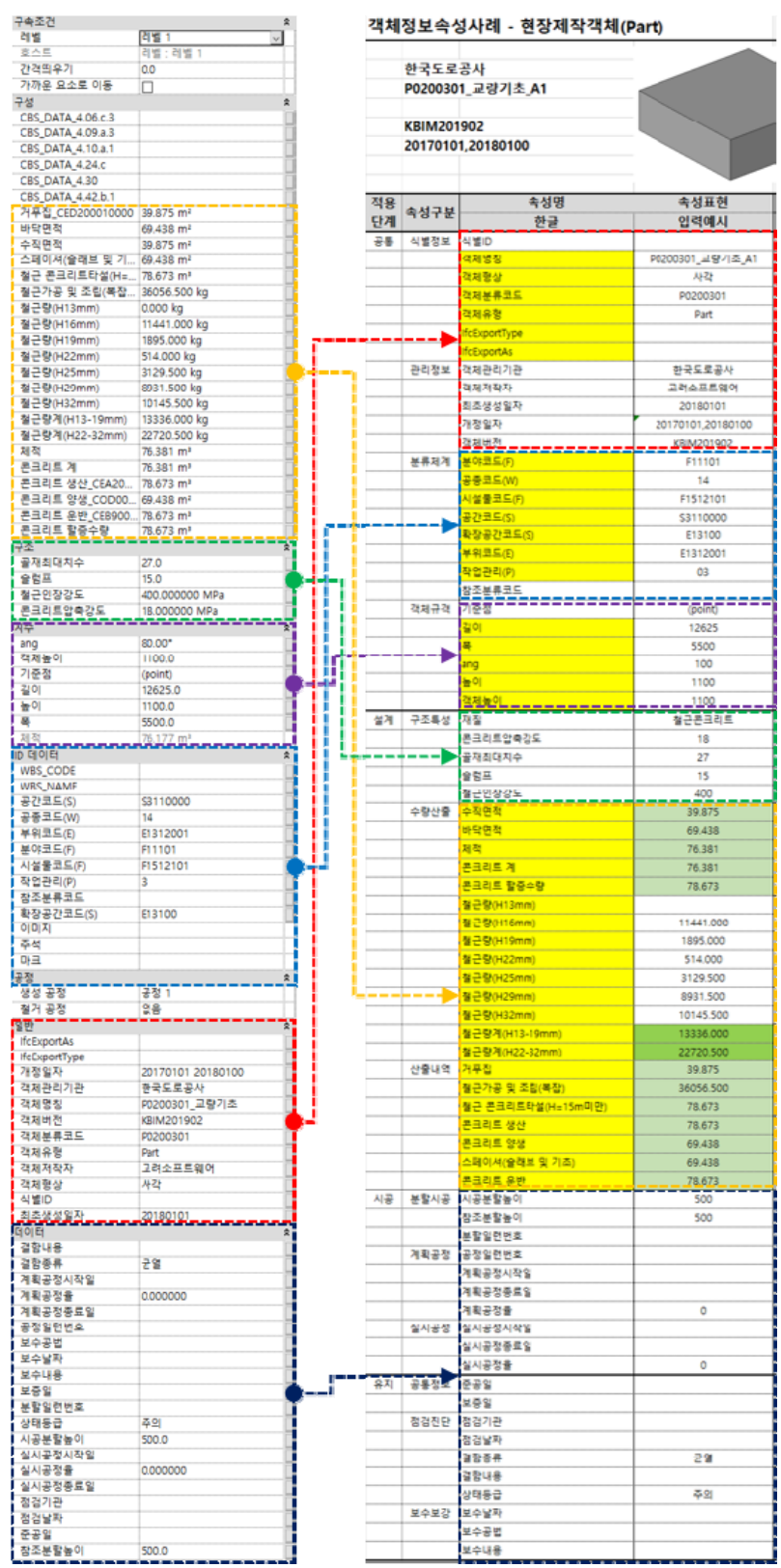

Fig. 9 Compared excel file and family property information

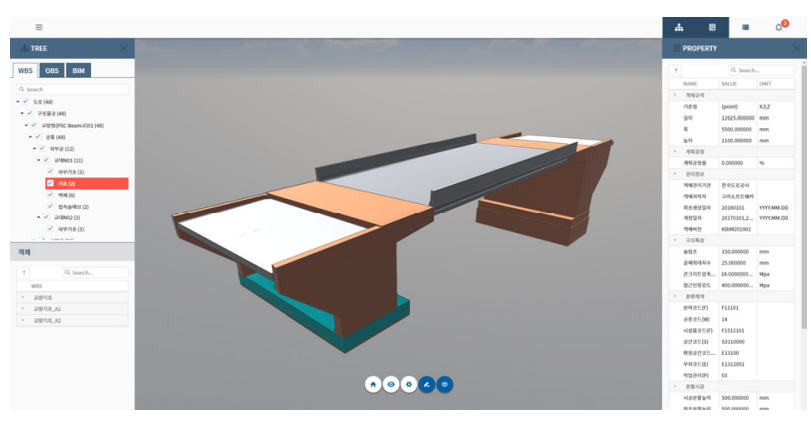

Fig. 10 BIM information classification system modeling verification

\section{3. 결 론}

본 연구는 선행 연구 조사 및 분석을 통하여 한국실정에 맞 는 속성분류체계(Nam and Kim, 2019)와 3차원 모델자동화생 성 방법(Lee et al., 2018)을 참고하여 BIM 속성분류체계를 따 르면서 Revit 프로그램에서 많은 속성항목과 많은 객체(패밀 리)를 신속하고 쉽게 입력하기 위한 프로그램을 개발하였다. 이는 선행 연구들과는 사용자 친화적인 Excel을 통하여 직관 적인 속성분류체계를 Excel sheet에 입력하고 본 연구에서 개 발된 프로그램을 통해서 대량의 BIM 속성을 신속하고 오류 없 이 작성 가능할 것으로 예상한다.

본 연구는 선행 연구들에서의 다양한 분류체계를 적용할 수 있도록 구현 방향을 잡았으며, 객체(패밀리)에 많은 속성항목 을 쉽고 빠르게 입력할 수 있는 프로그램 개발연구가 진행되어 선행 연구보다 한 단계 나은 결과물을 얻을 수 있었다.

이후 연구에서는 현재 제안한 방법과 상호 운용성(포맷 및 도구)을 개선하여 새로운 자동화 BIM 모델링을 추구하여야 한다. 초기 계획 및 설계에서 시설물 시공, 운영 및 유지보수, 최종 해체에 이르기까지 건설 수명주기의 모든 단계는 토목, 구조공학 및 시뮬레이션 응용(BIM), 분석을 위한 분야로 확장 되어야 한다.

\section{감사의 글}

본 연구는 국토교통부/국토교통과학기술진흥원의 지원으 로 수행되었습니다(과제번호 19SCIP-C121388-04).

\section{References}

Kang, T.W., Kim, J.E., Jung, T.S. (2016) Study on 3D Reverse Engineering-based MEP Facility Management Improvement Method, J. Korea Acad.-Ind. Coop. Soc., 17(8), pp. 38 45.

Lee, E.B., Kim, D.H. (2015) A study on the Implementation Method of the Object Classification System and Property Information for Vitalizing Standardized BIM Library, $J$. Archit. Inst. Korea, 31(12), pp.79 90.

Lee, J.M., Kim, H.S., Lee, I.S. (2018) Development of Automated 3D Modeling System to Construct BIM for Railway Bridge, J. Comput. Struct. Eng. Inst. Korea, 31(5), pp.267 274.

Lee, S.I., Han, J.S., Jo, C.W. (2015) A Basic Study on Property Structure Standardization based on BIM Information Framework, J. Archit. Inst. Korea, 31(5), pp.77 85. 
Nam, J.Y., Kim M.J. (2018) Object-oriented Road Field BIM Standard Object Classification System Suggest Development Plan, J. Korea Acad.-Ind. Coop. Soc., 19(3), pp.119 129.

Nam, J.Y., Kim M.J. (2019) A Study on the Development of BIM Property Classification System in Road and River Field, $J$. Korea Acad.-Ind. Coop. Soc., 20(2), pp.773 784.

Shin, J.H., Choi, J.S., Kim, I.H., Yoon, D.Y. (2016) A Study on Development of Integrated Management System for BIM Property Information, J. Korea Comput. Des. \& Eng., 21(2), pp.130 142.

Yu, J.H., Chin, D.B., Kang, B.C., (2011) Proposal for Standard Parameter System of Architecture Object on Revit, Proc. Korea of Comput. Des. \& Eng. Conf., Society for Computational Design and Engineering, pp.245 252.

\section{요 지}

$\mathrm{BIM}$ 도구는 설계프로세스에서 기술의 사용이 증가하면서 그에 따른 정보표준체계가 필요하게 되었다. 건설이 완료된 결과 (Result) 분류는 25종 단위시설에 327종의 유형, 결과를 구성하는 객체는 174종의 Part와 207종의 Component로 분류하고 있다. 선행 연구에서는 도로와 하천 분야 대상으로 속성분류체계를 대분류 4종, 중분류 13 종, 소분류 58 종, 속성정보 333 종으로 분류하였고, 객 체분류에 따른 대량의 속성정보를 입력하는 것의 소요 시간을 줄이는 것이 관건이었다. 따라서, Revit 플러그인과 같은 외부 응용 프 로그램 개발을 통해 구체적이고 반복적인 작업에 자동화가 필요하다. BIM 속성분류체계를 따르면서 사용자의 생산성과 편의성을 강 화할 수 있는 BIM 속성입력 프로그램을 구현하였다.

핵심용어 : BIM 분류체계, 속성, 속성입력 프로그램, 정보기술, 건설 